\title{
EL TRATAMIENTO GRAMATICAL DE LA VERDAD EN LA LENGUA ANDOQUE
}

$$
\begin{array}{r}
\text { John Landaburu } \\
\text { Docteur - es - lettres (Paris) }
\end{array}
$$




\section{RESUMEN}

Este artículo analiza las diversas funciones de una clase de palabras obligatoriamente presentes en la mayoría de los enunciados de la lengua andoque del Amazonas.

Todo enunciado asertivo -enunciado que afirma algo-, contiene en andoque una palabra llamada "asertivo". En un primer momento analizamos la función sintáctica del asertivo y la expresión de esta función. En un segundo momento describimos la forma de los distintos componentes del asertivo. En un tercer momento, analizamos el significado de estos componentes. Mostramos como los significados se articulan en una estructura conceptual referente al tratamiento de la verdad, a la credibilidad del enunciado, a la categorización del tiempo. En el centro mismo de la lengua se nos revela una preocupación rigurosa por la fundamentación epistemológica del discurso, preocupación mucho menos gramaticalizada en nuestras lenguas europeas.

Este trabajo es parte de los resultados de una investigación linguística entre la gente andoque, iniciada en 1970 con la ayuda de la Universidad de Los Andes de Bogotá y proseguida en 1973-1974 bajo los auspicios del Centre National de la Recherche Scientifique de París. La investigación ha dado lugar a varias publicaciones, entre ellas una descripción detallada de la lengua de los Andoques (cf. Bibliografía final). 


\section{INTRODUCCION}

\subsection{Los Andoques}

La pequeña comunidad andoque, compuesta por unos ciento cincuenta individuos, vive a orillas del río Aduche, afluente derecho del río Caquetâ, a unos treinta kilómetros abajo del chorro de Araracuara. El grupo parece ser el único sobreviviente en Colombia de una nación selvática importante establecida en el mismo territorio el siglo pasado. La población andoque fue caai aniquilada a principios de siglo por los precedimientos criminales de los eaucheros peruanos de la "Casa Arana". Se ha podido establecer que comprendía más de $\mathbf{1 0 . 0 0 0 ~ m i e m b r o s ~ a n t e s ~ d e ~ l a ~ l l e g a d a ~ d e ~ e s t o s . ~ E l ~ g r u p o ~ a c - ~}$ tual, como muchos otros grupos vecinos de la región entre el Caquetá y el Putumayo, procede de la reunión de unos pocos prófugos que se fueron buseando y decidieron volver a vivir en el territorio tradicional.

Los Andoques se llaman ellos mismos p^^sińh^ es decir, "gente del hacha". Parece ser que la gente andoque proveía a las naciones vecinas (huitoto-Murui, Muinane, Bora, etc... ) con hachas de piedra antes de la llegada de las hachas de acero. Eran los "dueños del hacha".

La lengua de los Andoques no tiene nombre especial. La llaman sus parlantes ke'õsofa "nuestro código, nuestro símbolo". Aunque varios autores la ugrupan dentro de la familia Huitoto, no parece que esta clasificación tenga fundamento linguístico. Seguimos provisionalmente considerando el Andoque como una lengua aislada.

\subsection{Datos fonológicos}

El análisis fonológico del andoque revela los resultados siguientes, fundamento del sistema de transcripción adoptado aquí:

Fonemas vocálicos

anteriores

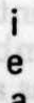

centrales

$\wedge$ posteriores

u

o

o 
Las vocales $i, e, a, 0,0$ pueden ser nasalizadas. La nasalidad se transcribe por medio de una tilde sobre la vocal. Ejemplo; $\tilde{\imath}, a ̃, \tilde{x}$. El orden central de las vocales da una sola vocal nasal: ã.

Todas las vocales pueden ser interrumpidas por un cierre glotal. El cierre glotal se transcribe por medio de un apóstrofe. Ejemplos: $i^{\prime}, a^{\prime}, \Lambda^{\prime}, \tilde{o}^{\prime}$, etc. ..

\section{Fonemas consonánticos}

LABIALES

APICALES

PALATALES POSTERIORES

oclusivo-fricativo oclusivo fricativo oclusivo-fricativo oclusivo-fricativo

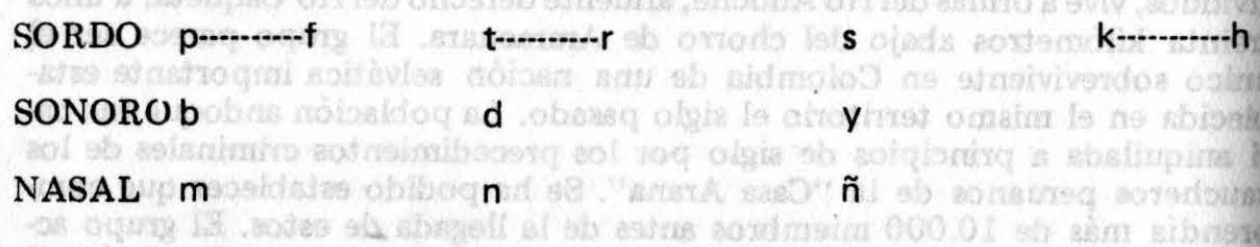

Aunque b y $\mathrm{m}$ por un lado, $\mathrm{d}$ y $\mathrm{n}$ por otro, puedan ser considerados como variantes de un mismo fonema (b se pronuncia $m$ delante de vocal nasal; $d$ se pronuncia $n$ delante de vocal nasal), se conserva una notación distinta para cada caso.

El fonema notado $f$ corresponde a una bilabial (El $\phi$ del A.F.I.). Los fonemas notados $s$ y $y$ tienen un margen de realización que va desde la africada hasta la espirante. $s$ tiene como variante a č delante de la vocal e.

El fonema notado $h$ es una espirante glotal.

\section{Prosodia}

La sílaba tiene siempre la composición siguiente:

$$
\mathrm{S}= \pm \mathrm{C}+\mathrm{V} \text { (Consonante opcional más vocal obligatoria) }
$$

El andoque es una lengua tonal. La sílaba puede tener un tonema alto o un tonema bajo. El tonema alto se transcribe por medio de un acento gráfico encima de la vocal: Ejemplos: ... . tá. . . í. . . pố. . . El tonema bajo no se transcribe. Los tonemas son unidades abstractas, como los fonemas, y se realizan de distintas maneras según el contexto. Las grandes reglas (las más comunes) de realización son las siguientes:

a) subir la altura musical de la sílaba que lleva acento escrito menos cuando esté comprendida entre una sílaba que lleva también acento y una pausa, y menos cuando esté comprendida entre dos sílabas acentuadas. b) no subir la altura musical de la sílaba no acentuada gráficamente menos cuando esté comprendida entre una sílaba acentuada y una sílaba no acentuada y menos cuando esté comprendida entre una sílaba no acentuada y una pausa (por ejemplo el final de un enunciado). En estos últimos casos la altura musical de la sílaba no acentuada es menos alta (media) que la altura de una sílaba acentuada.

Como cualquier fonema, el tonema sirve para distinguir unidades significativas. 


\section{EL ASERTIVO: FUNCION SINTACTICA}

Los enunciados asertivos de la lengua andoque, es decir los enunciado que tienen la estructura lógico-semántica de una aserción, contienen todo un tipo de palabra, formalmente identificable, que llamamos ASERTIVO.

\subsection{El asertivo tiene como función sintáctica representar en el enunciado
el elemento "focalizado".}

Como muchas otras lenguas, el andoque, tiene la capacidad de presentar un mismo contenido de distintas maneras según la voluntad del parlante poner en evidencia tal o cual aspecto. Si tomamos por ejemplo pariante de en la cual una mujer pega, un perro con un bastón, el ejemplo una situación construir su enunciado a partir del agente de laston, el locutor andoque puede

(1) ti’i mi ĩño yeĩbə^n ba'táisémá ĩpəkoa

//mujer/Asertivo/perro/quien-lo-golpea/bastón-con/casa-en// te de la situación.

(2) ĩño baya ti'i //perro/Asertivo/mujer/ella-golpea/bastón-con/casa-en//

"El perro es golpeado por la mujer con un bastón/casa-en// del instrumento de la situación la mujer con un bastón en la casa"; a partir

(3) bə.táisé bóya nimá ti'i ĩño yanibəńkã ĩpəkoa //bastón/Asertivo/que-con/mujer/perro/el-ella-golpea/casa-en//

"El bastón es con que la mujer golpea el perro en la casa"; a partir del lugar de la situación.

(4) ĩpəko bóya nie ti'i ĩño yanibəńkã bə'táisémá "/casa/Asertivo/que-en/mujer/perro/el-ella-golpea/bastón-con// acción desarrollada en la situación

(5) ĩpəkoa bn bə'táisémá ti'i ĩño yanibəni

//casa-en/Asertivo/bastón-con/mujer/perro/el-ella golpea//
"hay golpeada de el, perro,

Se llama "elemento focalizado" al aspecto del contenido a partir del cuol se construye el enunciado. Los cinco enun del contenido a partir del cua cuanto al contenido cuanto al contenido sino en cuanto al elemento focalizado.

Todo contenido asertivo puede ser descrito en general como la aplicación de uno o varios términos a plicación cinco enunciados presentados ejemplo, el contenido de los los cuatro términos (mujer, pero descrito como la asignación de une: la acción de golpear. tintas. En cuanto a la estructuración del contenido están, sin embargo, todos al mismo nivel, en oposición a la "relación". En andoque, los términos de relación son representados lingüísticamente por nombres (o substitutos nominales), las relaciones son representadas linguísticamente por verbos ${ }^{1}$. $\mathrm{Si}$ "foealizamos" un término de relación, tenemos un enunciado con enfoque nominal (cf, enunciados $1,2,3,4$ ); si focalizamos la relación, tenemos un enuneiado con enfoque verbal.

La existencia de esta función de focalización da una gran flexibilidad a la untaxis andoque. El castellano por ejemplo no suele focalizar sino sobre el igente y el paciente (vías activas y pasivas). Se llama "sujeto" a su elemento fucalizado. El enfoque verbal le es imposible.

\section{El asertivo representa en el enunciado el elemento focalizado.}

En contra de lo que se podría pensar a partir de la traducción, el elemento focalizado en cada uno de los enunciados presentados (por lo menos en los cuatro primeros) no está representado por la palabra correspondiente a: mujer, perro, bastón, casa; sino por la palabra debajo de la cual se ha escrito "Asertivo".

1.2. El elemento focalizado se expresa en el asertivo por medio de un! pronombre.

El nombre que representa el elemento focalizado no aparece nunca en el asertivo; lo que aparece es un pronombre que lo substituye. En los asertivos de los ejemplos, sucesivamente mi,baya,bóya,bóya,bn, está presente un pronombre que es la expresión sintáctica del elemento focalizado. La mención que se hace en estos mismos ejemplos del nombre al cual se refieren los pronombres no es necesaria. Si se sabe que estamos hablando de una mujer, de un bastón, de un perro, etc. . . no hay necesidad de explicitarlo y el asertivo aparece solo. Por ejemplo: bə’táisémá ĩpəkoa nibən^ baya

"El es golpeado por ella con un bastón en la casa".
Solo, o acompañado por su referencia nominal, el pronombre del asertivo es el que lleva la función sintáctica. Sería, por lo tanto, mejor traducir los ejemplos de la forma siguiente:

(1) "Ella, mujer, lo, perro, golpea con el bastón en la casa"

(3) "Ello, bastón, es con que ella, mujer, golpea él, perro, en la casa"

(4) "eso, casa, es en que ella, mujer, golpea él, perro con el bastón".

¿Qué pronombres representa el elemento focalizado?

Así como el castellano clasifica formalmente los nombres en dos clases o géneros: masculinos y femeninos, el andoque los clasifica en seis clases: 
- la clase No. 1 que abarca los nombres de materia, los fenómenos meteorologicos, los nombres abstractos, la mayoría de las plantas, algunos animales (serpiente coral, chicharra, raya, búho, golondrina, etc. .. ), seres míticos (fantasmas, sirenas, etc...), etc....

- la clase No. 2 que contiene casi exclusivamente árboles altos y leñosos y diversos elementos ligados a ellos metafóricamente o metonímicamente (sobre todo objetos alargados y rígidos),

- la clase No. 30 de elementos inanimados (visceras, objetos domésticos redondos o ahuecados), palmeras, otros árboles y otras plantas, etc. . .

- la clase No. 31 que contiene la mayor parte de las especies animales (incluyendo los astros), el hombre varón.

- la clase No. 32 que contiene unas pocas especies animales (murciélagos y ratones, marranos, oso hormiguero, colibríes y palomas, peces como la mojarra y el tucunaré), la mujer,

- la clase No. 33 que contiene la mayoría de los seres vivientes en tanto que son vistos como pluralidades (clanes y naciones, grupos de animales, la mujer en capacidad de procrear, el muerto, etc. . .).

Todo nombre andoque pertenece a una de estas seis clases y puede ser substituído por el pronombre correspondiente a su clase.

A un mismo nombre pueden corresponder varios pronombres dentro de la misma serie según la función requerida. El pronombre que aparece en el asertivo es el menos específico de todos. No es propiamente ni demostrativo ni anafórico.

Los pronombres que aparecen en el asertivo según la clase del elemento focalizado son:

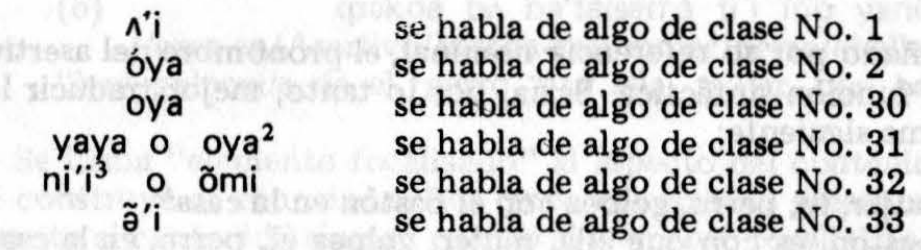

Si el elemento focalizado no es un nombre sino un personal (un objeto definido como partícipe de la situación de comunicación), su representación en el asertivo se expresa por una de las cuatro formas:

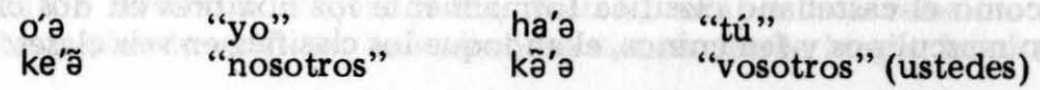

Estas doce ( 4 personales y 8 clasificatorios) formas corresponden a los doen el asertivo si el enfoque del enunciado es nominal.

$\mathrm{Si}$ el enfoque del enunciado es verbal (dirigido hacia la relación y no hacia los términos), el asertivo también contiene un pronombre, el pronombre $\wedge^{\prime}$ de la clase No. 1. Como si la relación o tal vez el contenido en general (el esde visto por la lengua como un sustantivo de clase No. 1. Precisamente la clase No. 1. es la menos definible de todas, la que contiene términos no individualizados, términos abstractos, etc. . .

\section{EL ASERTIVO: MORFOLOGIA}

1) Los pronombres que acabamos de presentar forman el núcleo del asertivo. En la construcción asertiva están obligatoriamente precedidos por un prefijo escogido dentro de la clase A:

$$
(A)=(\mathrm{b}-, \mathrm{kẽ}-, \mathrm{ma-}, \mathrm{k}-, \mathrm{d}-) \text {. }
$$

La unión de este prefijo y del pronombre forma el "asertivo mínimo" obligatoriamente presente en todo enunciado asertivo ${ }^{4}$. Tenemos:

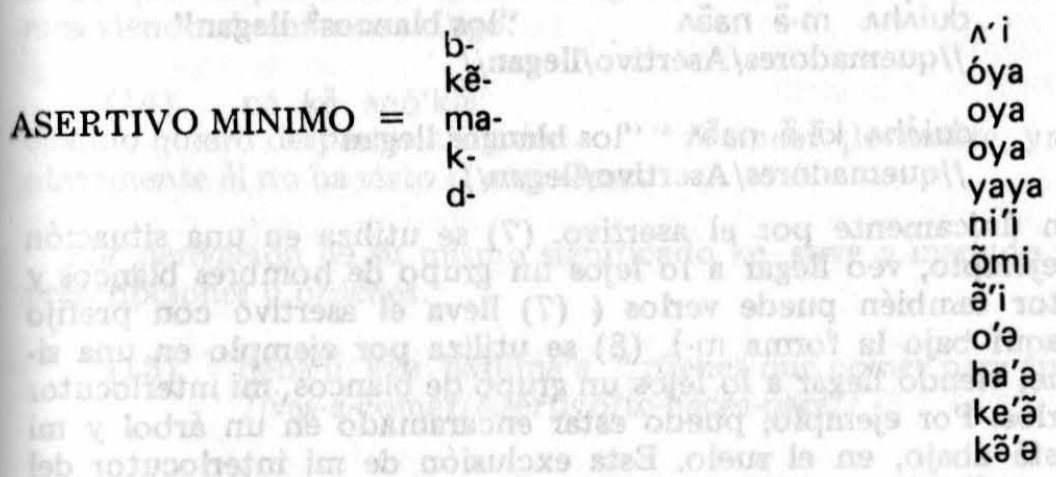

Son $5 \times 11$ combinaciones $=55$ formas efectivamente realizadas en la lengua. La unión de los términos de los dos paradigmas da lugar a varios fenómenos morfonológicos que no presentamos aquís. Es así como bfenomenos morfonologicos que no presentamos a mi (cf. enunciado 1); esta misma reducción se da en $b-\Lambda^{\prime} i=b \Lambda^{\prime} i$ redu cido a b^ (cf. enunciado 5$)$.

2) El asertivo mínimo puede ser seguido por varios sufijos pertenecientes a tres paradigmas o clases de escogencia sucesivos. En orden tenemos:

$$
\begin{aligned}
& \text { clase }(B)=(\phi \text { (cero), há }) \\
& \text { clase }(C)=(\Phi, k \text { ã }) \\
& \text { clase (D) = }(\phi \text {. ñé, pé })
\end{aligned}
$$


Todas las combinaciones posibles entre los términos de estos tres paradigmas (incluyendo los ceros) se realizan efectivamente en la lengua. El asertivo mínimo puede, por lo tanto, se seguido de $2 \times 2 \times 3=12$ sucesiones distintas.

3) Hay por lo tanto $12 \times 55=660$ asertivos distintos.

\section{EL ASERTIVO: SEMANTICA}

La morfología presentó cuatro clases de afijos posibles en el asertivo. $\mathrm{Pa}$ semos ahora a determinar el significado relativo de cada afijo dentro de su clase.

3.1. Semántica de la clase (A)

La clase (A) consta de cinco prefijos: b-, ke-, ma-, k-, d-. La estructura de sus significados se nos revela oponiéndolos dos a dos.

\section{Oposición b-/ kẽ-}

Los dos enunciados:

$$
\text { duiỉh^ m-ã naã^ "los blancos }{ }^{6} \text { llegan" }
$$

//quemadores/Asertivo/llegan//

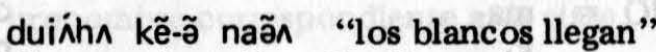
//quemadores/Asertivo/llegan//

se diferencian únicamente por el asertivo. (7) se utiliza en una situación en que, por ejemplo, veo llegar a lo lejos un grupo de hombres blancos y mi interlocutor también puede verlos ( (7) lleva el asertivo con prefijo b- realizado aquí bajo la forma $\mathrm{m}-$ ). (8) se utiliza por ejemplo en una situación en que, viendo llegar a lo lejos un grupo de blancos, mi interlocutor no puede verlos. Por ejemplo, puedo estar encaramado en un árbol y mi compañero está abajo, en el suelo. Esta exclusión de mi interlocutor del conocimiento va ligada a un refuerzo de mi propia autoridad: "Realmente, yo te lo digo, están llegando los blancos!". kẽ- viene casi siempre con un valor de afirmación enfática; marca de un conocimiento categóricamente afirmado.

Los sabios (chamanes) utilizan mucho kẽ- cuando se refieren a hechos que han podido conocer por una experiencia exclusiva de ellos (meditación, alucinación, etc. . . . En un canto ceremonial aparece este verso:

\section{(9) tu^ kẽoya "Son muy numerosos" (la gente es numerosa)}

El autor del canto afirma saber por experiencia propia que los habitantes de la tierra mítica son muy numerosos. Todo el mundo no ha podido ir a esa tierra. Un andoque regresando de Bogotá diría simplemente:
(10) tun boya "Son muy numerosos".

kẽ- se puede utilizar para reforzar el carácter subjetivo de una experiencia afectiva, experiencia por excelencia "privada", de la cual los astros están excluidos necesariamente. Cuando la boa del cuento siente que la danta que la está halando la va a partir en dos, se exclama:

\section{(11) b^’b^ nóbe'aikã kẽ'e "Papá, siento que me voy a desgarrar"} //papá/me voy a partir/Asertivo//

Ningún morfema expresa aquí la idea de sensación o de sentimiento. Sin embargo el enunciado siguiente:

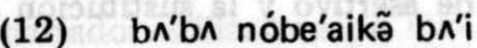

se hubiera traducido simplemente por: "Papá, me voy a desgarrar".

kẽ- dirige la atención del interlocutor hacia una experiencia escondida, no tangible para él. Si digo:

(13) pá b^ ^pó’kãi "ya amaneció" es porque la persona a quien estoy hablando estå despierta. Juntos estamos viendo el amanecer. Digo:

(14) pá kẽ ^pó'kãi

cuando quiero despertar a alguien. obviamente él no ha visto el amanecer.

Por derivación de su mismo significado kẽ- sirve a menudo para expresar prescripciones $u$ ordenes.

(15) hếba'ii kẽe hatiima'a “ ‘tienes que comer para crecer!” //vas-a-comer/Asertiva/te-haces-para//

\section{Oposición b-/k-y d-}

Los dos enunciados:

(16) tañe baya tãé'tú^ “Tañe es sabio"

(17) tañe kaya tãé'tún “¿Tañe es sabio?"

no difieren sino por el asertivo. El primero afirma un hecho conocido; el segundo expresa una pregunta. La contestación a (17) puede ser (16) o, más bien:

(18) tãé'tún baya tañe “ ¡Sĩ! Tañe es sabio”.

También puede ser, con el matiz analizado más arriba:

(19) tãé'tún kẽya tañe “¡Sí! yolo sé (tú, no), Tañe es sabio” 
El prefijo d- es una variante sintáctica de k-. k- se utiliza para saber si una aserción es verdadera o no; $d$ - se utiliza para pedir una precisión sobre un elemento desconocido de una aserción. La contestación a la pregunta con $k$. es: sí, no, tal vez, etc. . . La contestación a la pregunta con d-es un enunciado donde se da a conocer el elemento por el cual se preguntaba. Por ejemplo:

(20) kói daya tãé'tún "¿quién es sabio?" //quién/Asertivo/sabio//.

Los enunciados (16) o (17) pueden ser contestaciones a (20). Se pasa de (20) a (16) simplemente por el cambio de asertivo y la sustitución de un nombre al pronombre interrogarivo kói.

(21) hỉboka d^ hẽãi " ¿a dónde te fuiste?" //donde-a/Asertivo/te-fuiste//

\section{Contestación:}

(22) bogota ^boka b^ noãi "me fui a Bogotá".

La oposición k-/d- no es pues semántica sino sintáctica. Corresponde a la oposición tradicional entre "preguntas sobre el nexo" y "preguntas sobre los conexos".

El asertivo con prefijo k- o d- es frecuentemente seguido por el afijo -tá El significado de -tó aparece en oposición:

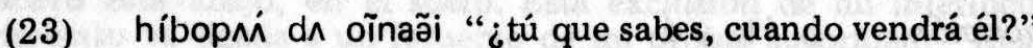
//cuando/Asertivo/el-vendrá//

(24) híbop^⿱ dıtá oĩnaãi “¿cuando vendrá, los sabes?”

La inclusión de -tá en el asertivo indica una incertidumbre en cuanto al saber del interlocutor. Es la formulación más corriente. Menos frecuente es la ausencia de -tó. Si pregunto al dueño del baile cuando se va a terminar éste, sin utilizar -tá, es porque supongo que ha decidido de su duración y por lo tanto sabe. Puedo emplear -tá y entonces no supongo que no sabe sino que no se si lo sabe o no. Puede no haber decidido, no querer decidir, etc... . -ta aparece al final del asertivo depués de todos los sufijos.

En conclusión, k- y d- se oponen a b- y a kẽ-por lo que se refiere a un estado de cosas desconocido.
3. Oposiciónk- od-/me-

Los dos enunciados:

$$
\begin{aligned}
& \text { hí daya "¿qué es esto?" } \\
& \text { hí maya "id." }
\end{aligned}
$$

no difieren sino en cuanto al asertivo. El primero es una pregunta, una interpelación a un interlocutor. El segundo no supone necesariamente la presencia de un interlocutor. Puede ser por ejemplo una interrogación que uno se hace a sí mismo. En los dos casos la relación al conocimiento no es la misma.

El narrador utiliza mucho ma-. Dice por ejemplo: "Un pájaro se encaramó. . . ¿qué pájaro era?. . ¡ah! ¡sí! era un pájaro carpintero. .. ". En esta deliberación utiliza ma-.

Como la interrogación "interpelativa" vista en el parágrafo anterior, la interrogación en ma- tiene dos variantes sintácticamente condicionadas. Si la pregunta se aplica sobre un elemento de la aserción, ma- funciona normalmente como un prefijo de asertivo (cf. enunciado (26)). Si la pregunta se aplica a la totalidad del enunciado (interrogación sobre el nexo) ma- se prefija al prefijo b-. Tiene entonces un valor netamente dubitativo.

Por ejemplo:

$$
\text { pá k^ oĩpó’kãi “¿ya ve?” (¿ya puede ver?) }
$$

se opone a:

$$
\text { pá mab^ oĩpó’kãi “¿será que ya ve?” }
$$

ma- no excluye necesariamente la interlocución. Le da a la pregunta un carácter más subjetivo. Puede ser utilizado como una pregunta atenuada, no directa. Por ejemplo un amigo mío va a visitar a alguien que estaba enfermo de la vista. Regresa y me cuenta que el enfermo lo ha reconocido.

Digo:

pá mab^ oĩpó’kãi “¿será que ya ve?”. Mi amigo me dice

(29) kãta pá b^ oĩpó'kãi ¡Pero claro! ¡él ve!”

Mi enunciado no era una pregunta; era una deliberación interna, un discurso dirigido hacia mí aunque lo hacía a voz alta. Mi amigo que lo oye exclama impacientemente: "¡pero claro que ve! ¡qué preguntas se hace Usted!". 
ma- no puede evidentemente excluir completamente al interlocutor; no sería linguístico. Oscila al tiempo sobre dos variables:

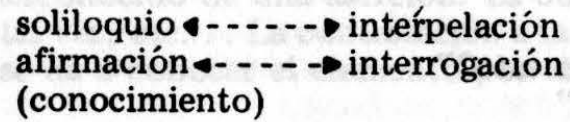

(ignorancia)

La interrogación directa (con k-o d-) implica una confesión de ignorancia La interrogación que uno se hace a sí mismo implica, para no ser absurda, alguna, aunque mínima, posibilidad de contestación.

\section{Conclusión}

Los significados de los cinco prefijos se definen en relación a dos variables: una variable crítica (fundamento o certidumbre de la aserción); una variable intersubjetiva (relación locutor-interlocutor). Tenemos el sistema:

\section{PRESENCIA}

DEL

OTRO

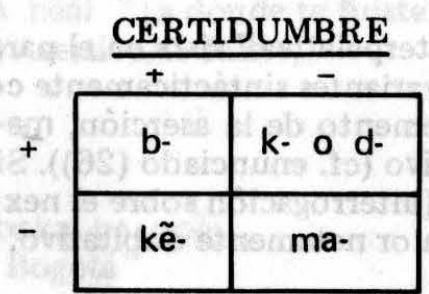

Si consideramos los valores secundarios de ke- y de ma- (afirmación categórica y estimación dubitativa), outenemos el sistema siguiente, más sencillo, definido por una sola variable: la afirmación de la verdad del enunciado:

\section{CONOCIMIENTO}

$\begin{array}{cccc}\begin{array}{c}\text { categórico } \\ \text { kẽ- }\end{array} & \text { positivo } & \text { probable } & \text { no-conocimiento } \\ \text { b- } & \text { ma- } & \text { k-od- }\end{array}$

\subsection{Semántica de la clase $(B)$}

La clase (B) consta de un afijo: -há. Oponiéndolo a su ausencia, podemos definir dos posiciones semánticas reconocibles en la diferencia de dos enunciados:

(30) fisói baya púkã oĩti^ "Fisioi ha hecho una canoa" //Fisi i/Asertivo/canoa/quien-lo-hace//

(31) fisiǿi baya-há púkã oĩti^ "dicen que fisix̄i ha hecho una canoa"

El enunciado (30) no lleva afijo después del asertivo mínimo. Se utiliza si el locutor ha tenido una experiencia directa del estado de cosas afirmado; por ejemplo si ha visto la construcción de la canoa. En el enunciado (31), el locutor no presenta una experiencia sino el relato de una experiencia acaecida a otro. "Me han contado que Fisioi ha hecho una canoa". No es necesario que el que me lo ha contado, haya tenido él mismo acceso directo al hecho; puede que se lo hayan contado a él también.

No hay que interpretar el efecto de -há como instaurador de un nuevo hecho: el "que me han contado tal hecho". (31) no es una aserción sobre el hecho de que me han relatado algo; (31) es una aserción sobre el mismo hecho que describe (30). Lo que añade (31) a (30) es que no lo sé por mi mismo sino porque me lo han contado. Esto queda demostrado en la combinación de -há con los prefijos interrogativos del asertivo.

(32) fisiọ́i kaya-há púkã oĩti^

no significa "¿es cierto que dicen que Fisioi ha hecho una canoa?" sino: "¿es cierto que, según dicen, Fisioi ha hecho una canoa?". La interrogación se aplica al hecho y no al dicho.

Las limitaciones de ocurrencia de -há proceden de su significado mismo. Por ejemplo al enunciado

(33) oba'ikã b^'i "estoy comiendo", no se opone ningún enunciado oba'ikã bshá

Si estoy comiendo, el hecho me es directamente perceptible. No me es conocido a través de un testimonio. -ha implica cierta distancia del locutor.

Como -há no instaura una afirmación sobre el testimonio sino el carácter de testimonio de una afirmación, se crean ciertas ambiguedades, aprovechadas por la lengua:

\section{(34) yẽ́p^kã b^há “dizque va a dormix"}

puede significar -lo mismo que la traducción con el giro "dizque"-, "dice que va a dormir" o "dicen que va a dormir". La primera traducción es frecuentemente aceptada. (34) significa normalmente "él dice que va a dormir" o también según un desliz semántico previsible, "el que quiere ir a dormir".

Este significado de "querer" es frecuente para -ha asociado a un verbo utilizado con intención de futuro..

(35) ĩño bayahá siyếbun "dizque va a matar un tigre"

\section{//tigre/Asertivo/el-va-matar//}

se traduce normalmente por "él quiere matar un tigre". Es comprensible que un testimonio sobre un hecho futuro (?!) se reduzca a una declaración de intenciones en cuanto al futuro. 
virtual sino por medio de la marca -hã̃ afectando a un enunciado con verbo en el mundo real. Como si el estado de-cosas al cual refiere el enunciado, fue-

Se puede añadir a la clase (B), el afijo -ni. Menos frecuente que -ha, -ni sil ve para indicar que un hecho no es ni observado, ni relatado sino inferido partir de otra observación o de otro testimonio. Se puede oponer:

\section{(36) kã'ãd bóya yidíıtákã "El arbol se cayó (lo vi caer)"}

a

(37) kã'ãda boya-ni yidı́^tákã

"el arbol se cayó (lo deduje)".

(37) puede usarse por ejemplo al ver el árbol al suelo. No lo ví caer pero si presencia en el suelo implica su caída. Los huerfanitos del diluvio sentado en el árbol ven despuntar el día en el oriente; saben que la luz significa par ellos el acceso a la condición humana; dicen:

(38)

\section{yó'h^ nãĩ'^ b^kẽãnib^}

"(llega la luz). por lo tanto nos vamos a volver hombres".

\section{Conclusión}

-ha, -ni-, $\phi$ permiten la atribución al enunciado de un valor crítico, en el sentido de una estimación del fundamento de su veracidad.

Se opnnen:

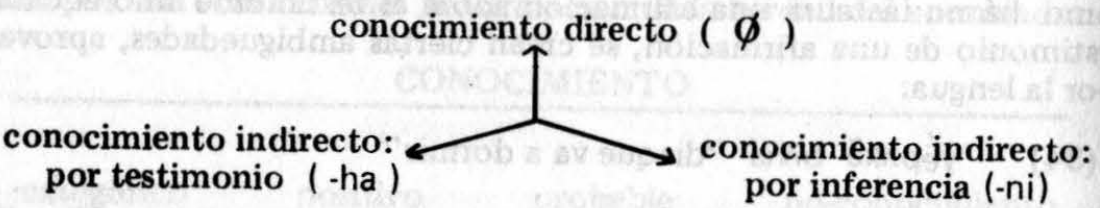

\subsection{Semántica de la clase $(C)$}

La clase $(C)$ consta de un sufijo: $-k$ ã. Oponiéndolo a su ausencia, podemos definir dos posiciones semánticas reconocibles en la diferencia de los dos enunciados:

(39) oba'ikã b^’i “estoy comiendo"

(40) oba'ikã b^kã “quiero comer"

$-k$ ã sirve para marcar un hecho no realizado, meta de una acción voluntaria. Un hecho no realizado se expresa normalmente en andoque por un cambio modal en el verbo (no hay dos modos: real y virtual). El proyecto de un hecho, aunque obviamente no realizado, no se expresa por medio del modo ra la voluntad de realizar tal cosa. - $k$ ã no puede aparecer con un verbo en el modo virtual. Significaría algo como proyectar la irrealidad (?).

-kã́ no designa un deseo en general sino la voluntad de realizar algo. "Deseo acariciarte" puede expresarse con -kẽ. mas no "deseo que me acaricies".

(41) haa b^-kã́ yõbai "deseo acariciarte"

(42) oa b^ yihẽ́bai nokãi “deseo (digo) que me acaricies".

Lo que, diferencia el proyecto del deseo es el ârea de acción del agente, su

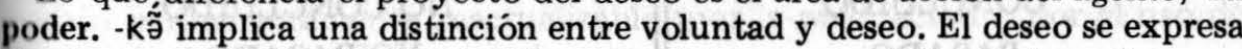
de otras maneras (inflexión verbal, proposiciones completivas, etc. .. )

\subsection{Semántica de la clase (D)}

La clase (D), última clase de afijos del asertivo se opone a tres posiciones $(-\varnothing,-$ ne, -pe ) que se refieren a la localización en el mismo tiempo del estado de cosas del que habla la aserción. Tenemos:

$$
\begin{aligned}
& \text { oba'ikã b^pé "comí hace tiempo" } \\
& \text { oba'ikã b^ñé "comí hace poco" }
\end{aligned}
$$

(45) oba'ikã b^'i "estoy comiendo".

pé implica que se está hablando de una época concluída. El acontecimiento puede haberse situado ayer, hace un año o hace cincuenta años. Lo importante es que ocurrió en una unidad de tiempo en la cual ya no estamos. La distancia del acontecimiento al momento de la enunciación varía relativamente al contexto.

-ñé implica que se está hablando de una época cercana. También puede variar la distancia temporal absoluta en relación al contexto. -ñé puede significar esta mañana, ayer o en el tiempo en que estamos viviendo. Normalmente se utiliza para un hecho ocurrido durante el día. Conviene anotar que en otro contexto gramatical (demostrativos), -ñé indica especialmente lo cercano a mí. Es normal que en el valor contexto del asertivo donde se sitúan acontecimientos, -ñe tenga un valor temporal. En el contexto nominal donde se sitúan objetos y seres, -ñé tiene un valor especial. Tiempo y espacio son especificaciones de una misma dimensión: proximidad-lejanía de la situación de comunicación.

La ausencia del afijo final (posición $\varnothing$ ) se define negativamente a las otras posiciones. $\varnothing$ indica que el acontecimiento, o estado de cosas del cual se está hablando, no ha concluído. -ñe y pé tienen una connotación perfectiva; la 
ausencia de -ñé o de -pé tiene una connotación imperfectiva. Que un esta. do de cosas no ha concluído puede implicar:

- que no ha empezado (futuro e irreal en general)

- que ha empezado y no ha concluído (presente)

- que no ha empezado ni va a concluir (permanente)

Esos son efectivamente los valores temporales que puede recibir un enun ciado sin afijo en la última posición del asertivo. La distinción ulterior de esos valores no es propia del asertivo sino del verbo. La categorización del tiempo en andoque se puede representar por el esquema:

\begin{tabular}{|c|c||}
\multicolumn{2}{c||}{ CONCLUIDO } \\
NO CERCANO & CERCANO \\
PASADO \\
-pé & -ñé
\end{tabular}

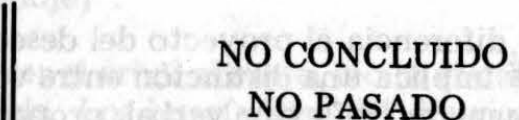

PRESENTE

FUTURO

Nota 1:

La categorización del espacio es paralela. Se opone el objeto situado en el espacio, al objeto no situado. El objeto no situado puede ser algo no situa. ble (abstracto), o algo que no se quiere situar. La marca del objeto situado es precisamente -'i, sufijo presente en los pronombres-núcleos del asertivo (cf. supra, final de 1.2). En el pronombre asertivo - $i$ indica que el objeto no es situado en el espacio sino focalizado por la mente. Los objetos pueden ser situados en dos áreas: una cercana al locutor, otra no cercana. Como para el tiempo, la cercanía o la no-cercanía son relativas.

Tenemos:

\section{SITUADO \\ ESPACIO}

NO CERCANO

-dí

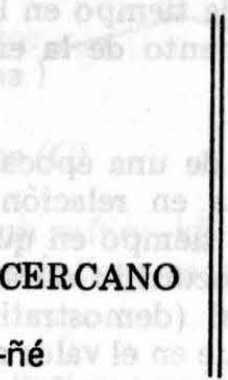

-ñé

\section{NO SITUADO}

MENTE

$-\mathbf{i}$
Nota 2:

Vemos cómo, en la categorización del tiempo, en la del espacio,en la del fundamento del conocimento (clase (B) que opone conocimiento directo a conocimiento indirecto), en la del grado de certidumbre (clase (A)), la oposición semántica constante es la de DEIXIS (área de comunicación) / NO DEIXIS.

\section{Nota 3:}

El relato mítico muestra un uso interesante de los afijcs de asertivo. La escogencia del sufijo revela la actitud del narrador acerca de la validez del mito. El uso de -ñé sitúa el mundo del mito en una temporalidad nuestra o cercana i la nuestra. El narrador utiliza -ñe para referirse a acontecimientos míticos absolutamente seguros para él. Si utiliza -háñé, quiere indicar que los acontecimientos míticos, indudables por otro lado, le han sido revelados por otros sabios. Sin embargo él los asume y los sitúa en nuestra temporalidad. pé no se puede utilizar para el mito; -pé sitúa los acontecimientos en un pasado histórico constatado por el locutor. Aunque el narrador haya "visto" los acontecinientos míticos, los ha visto en una esfera donde existen permanentemente. El mundo del mito no es un mundo lejano (pasado); es un mundo permanentemente reactualizable (por la meditación o por el uso de plantas sicotrópicas). Es un mundo cercano.

Si el narrador utiliza -hápé es que no quiere comprometerse en cuanto a la verdad del relato. -hápé sitúa los hechos en un pasado transmitido por tradieión oral. Los mitos contados con-hápé se vuelven semejantes a los relatos históricos y están sometidos como ellos a la duda que soporta cualquier testimonio no verificable. Fisiói, nuestro "profesor" de andoque nos dijo algún día:" -háñé es palabra de narrador seguro. Mi papá (Yiñé'kx, capitán de la tribu) dice ahora a menudo -hápé. Pero es porque la gente no pone el mismo cuidado. -hápé es palabra nueva para los mitos (îpníko = lo que vuelve padre); es como menos seguro".

\section{CONCLUSION}

El análisis morfológico del asertivo nos ha revelado la siguiente fórmula:

\section{CLASE A NUCLEO CLASE B CLASE C CLASE D}

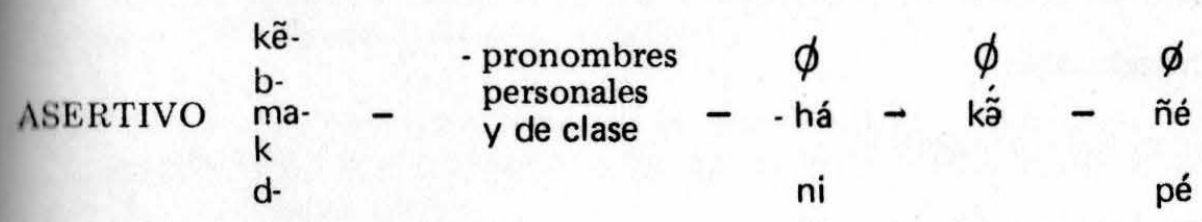

El análisis sintáctico-semántico nos ha revelado las funciones siguientes:

\section{ASERTIVO =}

CLASE A

Tipo de certidumbre

\section{NUCLEO}

elemento focalizado
CLASE B

fundamento crítico
CLASE C

volitivo

\section{CLASE D}

situación temporal 
${ }^{1}$ En otras lenguas, las "relaciones" pueden ser también representadas por adjetivos. El andoque no tiene adjetivos. Ciertas relaciones, muy generales (relación de inclusión, de localización, de posesión) no son representadas en andoque por verbos sino por sufijos de la declinación nominal.

${ }^{2}$ La clase N. 31 y la clase N. 32 tienen dos pronombres; el primero de uso normal, el segundo para representar un objeto ausente.

ni'i no existe fuera del asertivo. Todos los demas pronombres pueden ser utilizados para sustituir un nombre no necesariamente focalizado.

${ }^{4}$ De hecho existen enunciados asertivos sin asertivo. Su sintaxis sin embargo se deriva de la que describimos aquí (cf. "La langue des Andoke, $\oint \oint 127,128,158$ ).

5 cf. La langue des Andoke, $\oint \oint 174$ a 176.

${ }^{6}$ Los andoques llaman a los blancos duin'h^"quemadores". Probablemente aludiendo al arma de quemar duidi "la escopeta"... .

\section{BIBLIOGRAFIA}

LANDABURU Jon.

1975.

1976.
" L'énoncé en langue andoke: sujet ou focus?", Amerindia 1 , ed. SELAF, París.

"La tortue et le jaguar: conte andoke", A merindia 2, ed. SELAF, París.

La langue des Andoke (Amazonie colombienne), XXVI356 p., ed. SELAF, (en proceso de publicación).

LANDABURU Jon y PINEDA La Garza del centro de la tierra (Mitología de la gente Roberto.

Andoque del A mazonas colombiano), 230p., ed. UNES CO (en proceso de publicación).

RIVET Paul et WAVRIN Robert "La langue andoke", Journal de la Société des Américade. nistes de Paris tome XLI, p. 221-232, Paris. 1952 . 